\title{
Nipah Viral Virulence may be Due to Resistant Strains Amplified by Cross- Species Transmission between Animals and Humans
}

\section{Sisir Nandi*}

Department of Pharmaceutical Chemistry, Global Institute of Pharmaceutical Education and Research, Kashipur, India

\begin{abstract}
Nipah virus (NiV) is a newly emerging devastating viral infection that causes severe illness and loss of both animals and humans lives. Genetic resistant strains of NiV amplify the virulence through cross transmission between animals and humans. It is very dangerous and engulfs lives of people within short notice. The dearth of specific chemotherapeutics and vaccination lead to the study of dynamic viral strains. The present study represents an exploration of different NIV targets for the development of potential antiviral compounds. The manuscript describes more about the current scenario of death statistics, various NiV targets, available treatment options and research endeavors to discover a treatment strategy.
\end{abstract}

Keywords: Nipah virus (NiV); Virulence; Cross-species transmission between animals and humans; Drug targets; Genetically resistant strains.

\section{Introduction}

\section{Past pandemic and epidemic of $\mathrm{NiV}$}

Nipah virus is one of the ribonucleic acid viruses belong to the family members of Paramyxoviridae, genus Henipavirus. NiV was first originated from Sungai Nipah, a village in the Malaysian Peninsula where pig farmers became ill due to respiratory tract infection followed by encephalitis. NiV attacked pig farmers or abattoir workers which were first reported in September 1998 to April 1999 in Malaysia and then spread to neighbor Singapore by March 1999 [1,2] and in India and Bangladesh in 2001 [3]. Many 105 people died in Malaysia in April 1999, and one fellow was died in Singapore in the same year [1]. In 2001, a number of 45 persons were died followed by the death of 5 persons in 2007 in India whereas from 2001-2013 a number of 221 infected out of which 171 were being died in Bangladesh [4]. The morbidity and mortality statistics are given in Table 1.

The people in contact with the infected pigs get an infection. Infected people migrated in various countries and further infection speeded to Cambodia [5], Thailand [6], Indonesia [7], Madagascar in Southern Africa [8] and Ghana in West Africa $[9,10]$.

Infected people initially develop symptoms including fever, headaches, myalgia (muscle pain), vomiting and sore throat. This can be followed by dizziness, drowsiness, altered consciousness, and neurological signs that indicate acute encephalitis.

\section{Recent outbreaks in India in May 2018}

A recent outbreak at Kerala, India on May 31, 2018, recorded 18 deaths due to suspected Nipah virus infection. The death of three members of a family in Changaroth panchayat was confirmed as due to Nipah virus in the tests conducted at National Virology Institute, Pune. The latest victim suspected to have died due to Nipah infection is a lady of 31 years old, a nurse of the Perambra Taluk Hospital. She was taking care of the patients and was later confirmed to have Nipah infection at the Perambra hospital [11]. Scientists are worried due to lack of specific treatment to eradicate $\mathrm{NiV}$.

\section{Mode of treatments}

In vitro study confirmed anti-Nipah viral activity of ribavirin has been shown effective in vitro tests, but has not yet been proven effective

\begin{tabular}{|c|c|c|c|}
\hline Year & Country & Number of cases & Number of deaths \\
\hline $1998-1999$ & Malaysia & 265 & 105 \\
\hline 1999 & Singapore & Many & 01 \\
\hline $2001-2007$ & India & 71 & 50 \\
\hline $2001-2013$ & Bangladesh & 221 & 117 \\
\hline
\end{tabular}

Table 1: Morbidity and mortality in humans due to NiV, Malaysia-Singapore-IndiaBangladesh.

in humans and has to be passed in different clinical trials [12]. Passive immunization using a human monoclonal antibody that targets the Nipah G glycoprotein has been evaluated in the ferret model as postexposure prophylaxis $[13,14]$. The anti-malarial drug chloroquine was shown to block the critical functions needed for maturation of Nipah virus, although no clinical benefit has yet been observed [13]. m102.4, a human monoclonal antibody, has been used in people on a compassionate use basis in Australia and was in pre-clinical development in 2013 [13]. Favipiravir (T-705) is a purine analog antiviral approved for use in Japan against emerging influenza strains, and several phases 2 and 3 clinical trials are ongoing in the United States and Europe. Favipiravir has demonstrated efficacy against a broad spectrum of RNA viruses, including members of the Paramyxoviridae, Filoviridae, Arenaviridae families, and the Bunyavirales order. The scarcity of specific chemotherapeutics emphasizes the priority of exploring different targets of NiV. Dawes et al. reported that favipiravir has potent in vitro antiviral activity against Nipah and Hendra virus replication and transcription at micromolar concentrations [15]. Recently, the adenosine nucleoside analog GS441524, and its monophosphate prodrug GS-5734 were demonstrated to have in vitro antiviral activity against $\mathrm{NiV}$ and $\mathrm{HeV}$ with EC50 values between 0.49 to $1 \mu \mathrm{M}$ and 0.032 to $0.055 \mu \mathrm{M}$, respectively [16].

\section{Quest of different drug targets}

NiVhas The Nipahvirusisatype of RNAvirusin thegenusHenipavirus

${ }^{*}$ Corresponding author: Dr. Sisir Nandi, Department of Pharmaceutical Chemistry, Global Institute of Pharmaceutical Education and Research, Kashipur, India, Tel: +91 7500458478; E-mail: sisir.iicb@gmail.com

Received June 20, 2018; Accepted July 17, 2018; Published July 25, 2018

Citation: Nandi S (2018) Nipah Viral Virulence may be Due to Resistant Strains Amplified by Cross-Species Transmission between Animals and Humans. J Bioanal Biomed 10:93-95. doi:10.4172/1948-593X.1000213

Copyright: (@2018 Nandi S. This is an open-access article distributed under the terms of the Creative Commons Attribution License, which permits unrestricted use, distribution, and reproduction in any medium, provided the original author and source are credited. 
Citation: Nandi S (2018) Nipah Viral Virulence may be Due to Resistant Strains Amplified by Cross-Species Transmission between Animals and Humans. J Bioanal Biomed 10:93-95. doi:10.4172/1948-593X.1000213

having a morphology similar to other paramyxoviruses with pleomorphic structure, herringbone nucleocapsids, and $10 \mathrm{~nm}$ long surface protein spikes on the envelope (Figure 1). Ribonucleic acid of $\mathrm{NiV}$ is well settled within the lipid bilayer coat containing six genes such as N, P, M, F, G and L responsible for producing nucleoprotein, phosphoprotein, matrix, fusion, glycoprotein and large RNA polymerase [17]. Complex formation between nucleoprotein and phosphoprotein component viral chaperone is responsible for the viral replication. Such complex is called as $\mathrm{N}^{0}-\mathrm{P}$ core complex, the crystal structure of which was solved by Yabukarksi and colleagues [18].

The NiV G and F proteins mediate the entry of genome, attachment, and fusion with the host receptor cells [19]. Ephrin-B2 (EFNB2) was recognized as a human host cellular receptor for the attachment of NiV glycoproteins. Such attachment is mediated by the sialic acid interactions having phenylalanine side chain on EFNB2 that fits snugly into a hydrophobic pocket on the viral protein [20]. The fusion protein, an enveloped glycoprotein essential for viral entry, belongs to the family of class I fusion proteins and is characterized by the presence of two heptad repeat (HR) regions, HR1 and HR2. These two regions associate to form a fusion-active hairpin conformation that juxtaposes the viral and cellular membranes to facilitate membrane fusion and enable subsequent viral entry. The Hendra and Nipah virus fusion core proteins were crystallized by Lou and co-workers [21]. Matrix protein is situated beneath the lipid bilayer and helps to connect with the viral RNA that is accountable for the formation of its virions particles responsible for the virulence effect causing gene expression and immune evasion.

\section{Mode of spreading of $\mathrm{NiV}$ infection}

Fruit bats have an affinity to taste the pulpy fruits such as bananas, mangos, dates, avocados, guava, papaya, figs and wild dates bearing thin peel as well as some vegetables like a banana flower and bean flower. $\mathrm{NiV}$ is being transmitted by the bats that feed on or touches. Figure 2 denotes fruits bat eating guava (A), banana (B), date palm $(C)$, papaya $(D)$, mango $(E)$, figs $(F)$, the flower of banana $(G)$ and beans $(\mathrm{H})$. Humans and animals eat the infected fruits and transmission of the disease occurs.

Fruit bats live at the date and palm trees. Date palm sap is so delicious and collected by the villagers who climb the tree and come in touch with the virus. Date palm sap can be infected by the saliva and excretory materials secreted by the fruit bats containing NiV. Figure 3

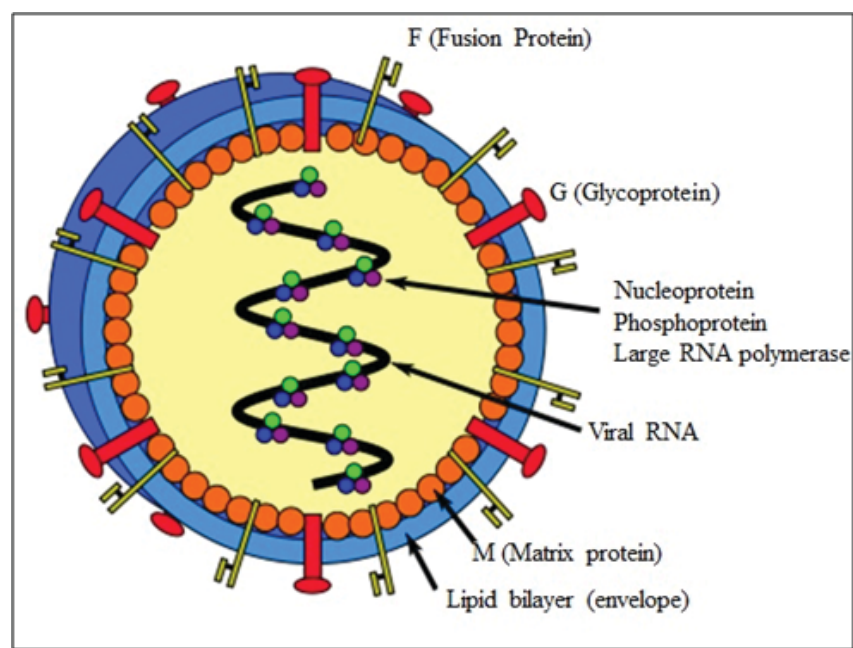

Figure 1: Structure of a Henipavirus [15].

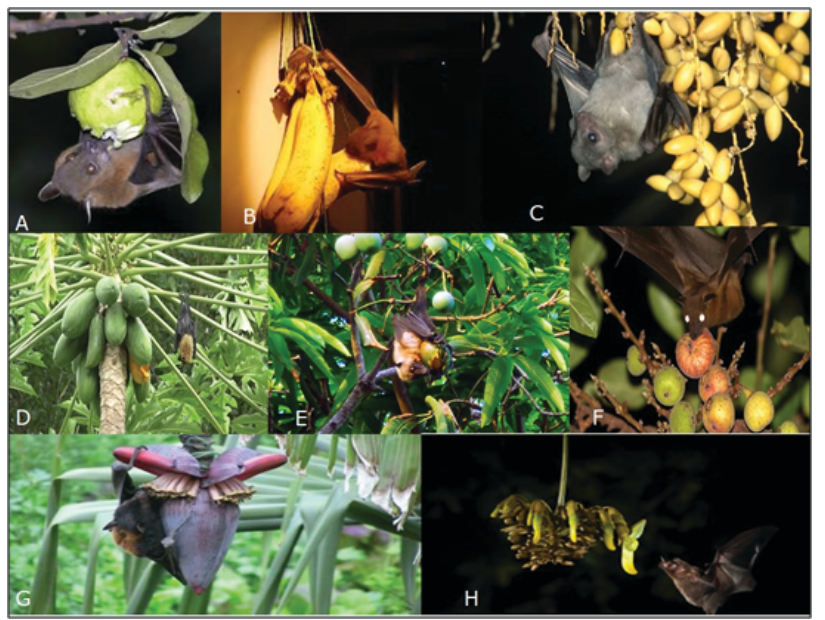

Figure 2: Fruits bat eating guava $(A)$, banana $(B)$, date palm $(C)$, papaya $(D)$, mango $(E)$, figs $(F)$, a banana flower $(G)$ and beans $(H)$.

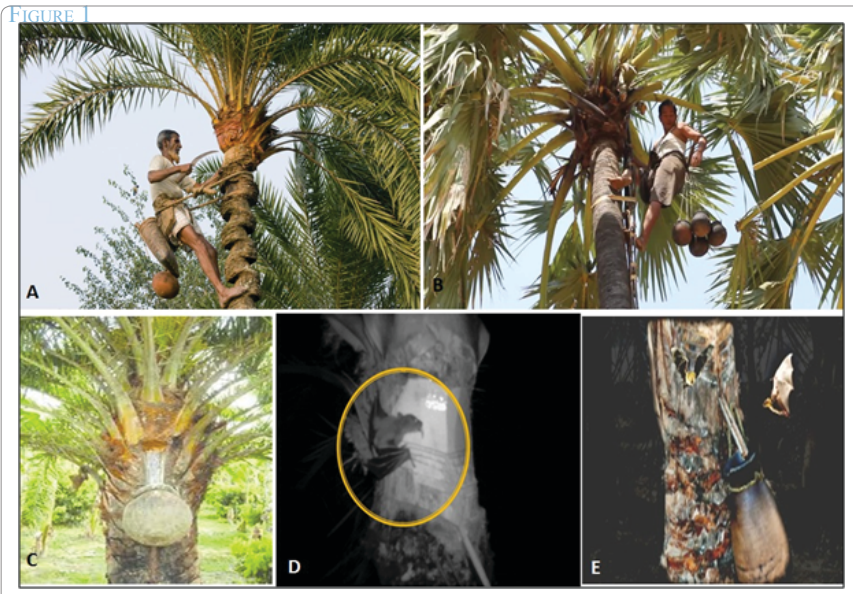

Figure 3: A villager collects date palm sap (A), palm sap (B), in a clay pot $(C)$ and fruits bats attacking stem of the date tree (D) and sap (E).

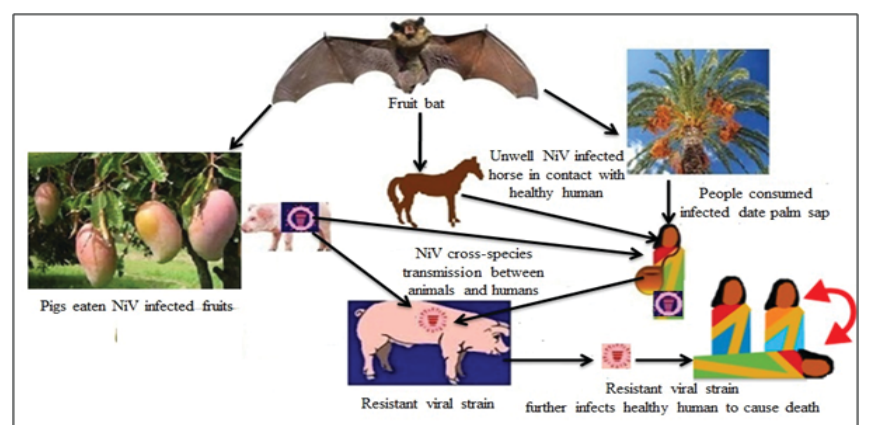

Figure 4: Mechanisms of NiV resistant strain.

indicates the villager collects date palm sap (A), palm sap (B) in a clay pot $(C)$, and fruit bats attacking stem of the date tree (D) and sap (E).

Luby et al. [22] suggested that $\mathrm{NiV}$ was transmitted from fruit bats to persons through drinking fresh date palm sap. Date palm sap occasionally contaminated with $\mathrm{NiV}$-infected bat urine or saliva that contains a sufficient dose of $\mathrm{NiV}$ to be fatal to humans. In India, in a bat sample survey, NiV RNA was detected in a liver homogenate of fruit 
Citation: Nandi S (2018) Nipah Viral Virulence may be Due to Resistant Strains Amplified by Cross-Species Transmission between Animals and Humans. J Bioanal Biomed 10:93-95. doi:10.4172/1948-593X.1000213

bats captured in Myanaguri, West Bengal [23].

\section{Expert's Opinion}

Deforestation leads to the destruction of natural habitat followed by global warming and ecological imbalance which may cause homeless to the fruits bats, also called as flying foxes, who moved to the neighbor states and countries. Fruits bats of the genus Pteropus close in contact with the pigs came into the picture as a carrier of NiV. The natural reservoir of fruit bats is $\mathrm{NiV}$ and the carrier is animals such as pigs and horses. $\mathrm{NiV}$ is transmitted into the healthy humans in close contact with the infected pigs and horses or upon the consumption of contaminated fruits and date palm sat. Then viral strains cross-transmission between humans and these animals cause genetically resistant strains which are so dreadful (Figure 4). When these animals sneeze, cough, secrete tears and passing stools, the resistant viral strains may come out through their nasopharyngeal secretions, tears, and intestinal diarrheal materials and can infect the healthy humans in close contact with this contaminated environment having viral genetic mutant drift particles. The virus is transmitted from the carrier (horses and pigs) to humans through consumption of contaminated fruits or upon contact with the respiratory droplets or body fluids of infected animals. This appears to be a case of cross-species transmission (CST) [24] of a same strain of virus between different organisms which produces resistant strains rather than genetic re-assortment. Cross-species transmission causes amplification to the gene mutations leading to generate highly resistant $\mathrm{NiV}$ strain which is responsible for the $\mathrm{NiV}$ virulence that may overcome the host immune defense mechanism. It has been assumed that a Keralian nurse died due to infection with the dangerous resistant $\mathrm{NiV}$ strain. Further genomic scientists can analyze the genome of dangerous viral strains which would be helpful for the development of anti-Nipah viral drug and vaccination. More attention has to be paid and more actions need to be taken to prevent and treat the Niv infection. The healthy people may bear Biomask. BioMask antiviral face mask is an essential protective device in healthcare today, giving clinicians and patients a level of safety and security now attainable (Figure 4).

\section{Conclusion and Future Direction}

Pulpy fruits such as bananas, mangos, dates, avocados, guava, papaya, figs and wild dates bearing thin peel as well as some vegetables like a banana flower and bean flower having a great affinity of the fruit bats attacking should be avoided to prevent the infection. There is no drug or vaccine developed yet to kill the NiV. To explore anti-NiV compounds, different drug targets have been studied.

Inhibitions of $\mathrm{N}^{0}-\mathrm{P}$ core complex, sialic acid binding domain and hairpin conformation has to be taken into consideration as potential targets for the development of antiviral compounds against NiV. Sialic acid congeneric small molecules could be designed, synthesized and tested against NiV glycoprotein. Prior to the experiment, such compounds could be docked inside the NiV G target cavity for the prediction of binding affinity of the ligand towards the target.

The healthy human infected with the primary NiV strain suffer from severe encephalitis with viral fever but may not be dying. Crossspecies transmission between animals to humans and the human-tohuman transmission through droplet infection led to the secondary infection due to producing resistant viral strains. The patients suffering from a secondary infection caused by the virulent resistant strain may be died due to loss of the immunity. Therefore, dangerous resistant $\mathrm{NiV}$ strain is a major target to explore its genome sequences for the design and discovery of anti-Nipah viral drug and vaccine. Existing antiviral drugs could be repurposed to test against $\mathrm{NiV}$.

\section{Acknowledgements}

The author sincerely acknowledges the valuable comments of the anonymous Reviewers that helped to improve the quality of the final manuscript.

\section{References}

1. CDC (1999) Outbreak of Hendra-like virus - Malaysia and Singapore 19981999. Morb Mort Weekly Report 48: 265-269.

2. Paton NI, Leo YS, Zaki SR, Auchus AP, Lee KE, et al. (1999) Outbreak of Nipahvirus infection among abattoir workers in Singapore. Lancet 354: 1253-1256.

3. WHO (2004) Nipah virus outbreak(s) in Bangladesh, January-April 2004. Wkly Epidemiol Rec 79: 168-171.

4. Kulkarni DD, Tosh C, Venkatesh G, Senthil Kumar D (2013) Nipah virus infection: current scenario. Indian J Virol 24: 398-408.

5. Reynes JM, Counor D, Ong S, Faure C, Seng V, et al. (2005) Nipah virus in Lyle's flying foxes, Cambodia. Emerg Infect Dis 11: 1042-1047.

6. Wacharapluesadee S, Lumlertdacha B, Boongird K, Wanghongsa S, Chanhome L, et al. (2005) Bat Nipah virus, Thailand. Emerg Infect Dis 11: 1949-1951.

7. Sendow I, Field HE, Darminto CJ, Morrissy C, Meehan G, et al. (2006) Henipavirus in Pteropus vampyrus Bats, Indonesia. Emerg Infect Dis 12: 711 712 .

8. lehle C, Razafitrimo G, Razainirina J, Andriaholinirina N, Goodman SM et al. (2007) Henipavirus and Tioman virus antibodies in pteropodid bats, Madagascar. Emerg Infect Dis 13: 159-161.

9. Drexler JF, Corman VM, Gloza-Rausch F, Seebens A, Annan A, et al. (2009) Henipavirus RNA in African bats. PLoS ONE 4: e6367.

10. Hayman DTS, Suu-Ire R, Breed AC, McEachern JA, Wang L, et al. (2008) Evidence of Henipavirus infection in West African fruit bats. PLoS ONE 3 . e2739.

11. https://timesofindia.indiatimes.com/city/kozhikode/kerala

12. Vigant F, Lee B (2011) Hendra and nipah infection: pathology, models and potential therapies. Infect Disord Drug Targets 11: 315-336.

13. Broder CC, Xu K, Nikolov DB, Zhu Z, Dimitrov DS, et al. (2013) A treatment for and vaccine against the deadly Hendra and Nipah viruses. Antiviral Res 100 8-13.

14. https://www.cdc.gov/vhf/nipah/index.html

15. Dawes BE, Kalveram B, Ikegami T, Juelich T, Smith JK, et al. (2018) Favipiravir (T-705) protects against Nipah virus infection in the hamster model. Sci Rep 8: 7604

16. Lo MK, Jordan R, Arvey A, Sudhamsu J, Ranjan PS, et al. GS-5734 and its parent nucleoside analog inhibit Filo-, Pneumo-, and Paramyxoviruses. Sci Rep 7: 43395

17. Chan YP, Chua KB, Koh CL, Lim ME, Lam SK (2001) Complete nucleotide sequences of Nipah virus isolates from Malaysia. J Gen Virol 82: 2151-2155.

18. Yabukarksi F, Lawrence P, Tarbouriech N, Bourhis JM, Delaforge E, et al. (2014) Structure of Nipah Virus Unassembled Nucleoprotein in Complex with its Viral Chaperone. Nat Struct Mol Biol 21: 754-759.

19. Tamin A, Harcourt BH, Ksiazek TG, Rollin PE, Bellini WJ, et al. (2002) Functional properties of the fusion and attachment glycoproteins of Nipah virus. Virology 296: 190-200.

20. Bowden TA, Aricescu AR, Gilbert RJ, Grimes JM, Jones EY, et al. (2008) Structural Basis of Nipah and Hendra Virus Attachment to Their Cell-Surface Receptor Ephrin-B2. Nat Struct Mol Biol 15: 567-572.

21. Lou Z, Xu Y, Xiang K, Su N, Qin L, et al. (2006) Crystal structures of Nipah and Hendra virus fusion core proteins. FEBS J 273: 4538-4547.

22. Luby SP, Rahman M, Hossain MJ, Blum LS, Husain MM, et al. (2006) Foodborne Transmission of Nipah Virus, Bangladesh. Emerg Inf Dis 12: 1888-1894.

23. Yadav PD, Raut CG, Shete AM, Mishra AC, Towner JS, et al. (2012) Detection of Nipah virus RNA in fruit bat (Pteropus giganteus) from India. Am J Trop Med Hyg 87: 576-578.

24. Parrish CR, Holmes EC, Morens DM, Park EC, Burke DS, et al. (2008) CrossSpecies Virus Transmission and the Emergence of New Epidemic Diseases, Microbiol Mol Biol Rev 72: 457-470. 